\title{
The Role of Academic Health Centers in Improving Health
}

\author{
William L. Roper, $M D, M P H^{1}$ \\ Warren P. Newton, MD, MPH \\ ${ }^{1}$ Vice Chancellor for Medical Affairs, \\ The University of North Carolina at \\ Chapel Hill, Chapel Hill, NC \\ ${ }^{2}$ Chair, Department of Family Medicine, \\ School of Medicine, The University of North \\ Carolina at Chapel Hill, Chapel Hill, NC
}

Conflicts of interest: none reported

\section{CORRESPONDING AUTHOR}

William L. Roper, MD, MPH

School of Medicine

The University of North

Carolina at Chapel Hill

125 MacNider Hall

Chapel Hill, NC 27599-7000

bill_roper@med.unc.edu
Ann Fam Med 2006;4(Suppl 1):S55-S57. DOI: 10.1370/afm.562.

\section{INTRODUCTION}

mprovements in health do not occur in isolation: they happen most readily when the clinical and biomedical intersect, or when efficacy and effectiveness come together, as described in "The Michigan Clinical Research Collaboratory: Following the NIH Roadmap to the Community."1 In this commentary, we expand on the lessons described in that case study, with particular emphasis on the most effective role that we see for academic health centers (AHCs).

\section{GUIDING FOCI}

What, then, is the role of the AHC in the process of improving health? What should their central task be? The answer to these questions lies in yet another question: How do we improve the health of the population? The Association of American Medical Colleges' slogan is "Tomorrow's doctors, tomorrow's cures" - a slogan that is punchy and helpful, but nonetheless carries with it the implication that the major emphasis of this organization's effort is basic biomedical research, pushing back the frontiers of knowledge and affecting individual patients. This focus misses the perspective of health at the population level—a focus that is as important as the exciting biomedical advances that garner so much attention. We think that the work of AHCs should be guided by 3 overarching foci, as follows.

First, successful improvements in health occur when we are able to move out of the laboratory and into the community-when, in other words, we make the journey from efficacy to effectiveness. We are rightly proud of our efforts within the walls of our laboratories and general clinical research centers to find treatments that are efficacious in saving lives. But every day, our physicians and our medical students face considerations not addressed in controlled clinical research - the many patients with comorbidities who would have been excluded from the research altogether, patients who may not have insurance, and those who struggle to appropriately follow a medication regimen absent the attention of research nurses who also ensure that follow-up visits occur. We need more explicit focus on translating our work from efficacy to effectiveness.

Second, our health system today also focuses too much on acute care, despite ample evidence of the benefits of preventive care ${ }^{2}$ and of the ability of public health interventions to change health practice. ${ }^{3}$ Public health measures have had an effect on clinical medicine in numerous areas, including maternity care, coronary heart disease, and cancer. ${ }^{4}$

Third, we need to take much more forceful action to address the profound health disparities that exist in our population. ${ }^{5,6}$ Differences in 
access to care and in outcomes by population characteristics are unacceptable and must be addressed systematically and urgently.

\section{SOURCES OF FUNDING}

Making any of these important changes, however, requires adequate funding. Where, then, can the resources come from to improve the health of the population? There are essentially 4 key collaborators with AHCs in conducting research and practice efforts: the National Institutes of Health (NIH), the Agency for Healthcare Research and Quality (AHRQ), the Centers for Disease Control and Prevention (CDC), and the pharmaceutical industry. Their budgets combined reflect the maximum possible investment in research for health improvement-some of which is available to AHCs as extramural funding.

The source of funding most commonly associated with AHCs is NIH, which has a 2006 budget of approximately $\$ 30$ billion. In contrast, the AHRQ, tasked with identifying and implementing system improvements related to health care quality and safety, has a budget of $\$ 300$ million-an amount that is merely a rounding error in the NIH budget. The budget of the CDC_-an entity whose work focuses primarily on public health research and practice-is now about $\$ 8$ billion. ${ }^{7}$ Schools of public health have a long history of relationships with the CDC, and its ties to medical schools have been growing. If we are going to be serious about improving the health of the population, the CDC will necessarily be an increasingly important partner. Finally, the pharmaceutical industry's research and development spending, which is often closely aligned with AHCs, is estimated at about $\$ 40$ billion. $^{8}$

Each of these potential funding sources is dwarfed, however, by the budget for the Centers for Medicare and Medicaid Services, which has an annual budget of more than one half of a trillion dollars. ${ }^{7}$ It is true that those resources are directed at the care of individual patients, but they are resources that are available to us as a nation for improving the health of the population. The lessons from the UK's National Health System (NHS) are germane. For example, by relying on a robust primary care system and using pay for performance and greatly expanded informatics, that system has been able to increase dramatically the use of statins for patients with coronary artery disease over several years in practices across the country ${ }^{9}$ - a stunning achievement and one with substantial implications for the health of the population. Of course, the NHS is very different from the US health care system, and we are not suggesting wholesale adoption of NHS approaches. But pay attention-Mark McClellan, administrator of the Centers for Medicare and Medicaid Services, and his colleagues there are serious about making fundamental changes. We expect to see dramatic and effective shifts on the horizon.

\section{LEADERSHIP ROLE}

So having laid out the overall goals and identified potential funding sources, where does that leave us regarding the role of our AHCs in improving the health of the population? Our job is to lead in the transformation of health care. We have in one place the most transformative research occurring - and often the responsibility to care for the most vulnerable in our population. Yet, our institutions are, in many respects, the most conservative part of the health care system, conservative in the sense that fundamental change is very difficult. It is no accident that a recent Robert Wood Johnson Foundation study on clinical quality improvement stated that substantial clinical change is "orders of magnitude" harder in academic centers than in private settings. ${ }^{10}$ Most major medical centers see the path to greatness as national excellence in biomedical research. We assert that we ought to strive for excellence through regional effectiveness as well-in other words, in how successful we are at improving the health of the population in the geographic areas around us.

\section{PARTNERSHIPS AND INFRASTRUCTURE}

To be the leaders in improving health at the population level, AHCs will need to identify new kinds of research questions to guide us. The article by Schwenk and Green ${ }^{1}$ provides one map of how this can be achieved. It demonstrates the importance of deep involvement in system change both within and outside of our institutions. Our neighbors in surrounding counties and statewide are appropriate partners for us, and partnership means a reciprocal relationship, in which we recognize that we are part of a bigger system and do not have a monopoly on good ideas.

Investing in these kinds of partnership activities also requires that we attract and retain faculty with a kind of expertise different from the kind that may be most familiar to us. For example, faculty should be responsive to being rewarded for improving the quality of the care they provide, with health outcomes among their patients playing into questions of tenure and promotion.

We will also need other kinds of infrastructure, with strong linkages to primary care in the community and also to established public health institutions, to insurers, and to other payers, remembering 
that maintaining and enhancing those kinds of connections is not free. New organizational units and processes within the AHC are necessary; for example, in a new approach, networking ability and computer services become increasingly critical, and issues of community saturation are commonly in the conversation.

\section{INVESTMENTS}

These new directions will require substantial investment, analogous to the investment that academic centers have made over the last generation in basic biomedical research. For example, the successes at Michigan were built on 10 years of well-funded, community-based research projects. ${ }^{1}$ That institution also had the benefit of a central infrastructure in new clinical and administrative information systems that permits more real-time monitoring of population health and innovation, and new organizational structures that support research outreach. As the Michigan experience shows, some of the essential investment will be "brick and mortar," but more will be in information technology and other "soft links"; this investment in turn requires new ways to deploy capital. In many settings, it is easier to get funding for new buildings and specific high-ticket equipment than to get large amounts of operational funding.

Ultimately, to improve the population's health and to be leaders in the transformation of health care, we will have to push ourselves outside of our comfort zone. Academic medicine must evolve dramatically. Regardless of specialty, it is time to change, time to develop new skills, and time to take the lead.
To read or post commentaries in response to this article, see it online at http://www.annfammed.org/cgi/content/full/4/suppl_1/s55.

Key words: Academic health centers; public health; organizational change; funding; financial support; partnerships; infrastructure

Submitted January 16, 2006; accepted April 5, 2006.

\section{References}

1. Schwenk TL, Green LA. The Michigan Clinical Research Collaboratory: following the NIH Roadmap to the community. Ann Fam Med. 2006;4(Suppl 1):S49-S54.

2. US Preventive Services Task Force. Guide to Clinical Preventive Services. 2nd ed. Washington, DC: Office of Disease Prevention and Health Promotion, US Government Printing Office; 1996.

3. Task Force on Community Preventive Services. Preventive Services: What Works to Promote Health? New York, NY: Oxford University Press; 2005.

4. Centers for Disease Control and Prevention. Ten great public health achievements-United States, 1990-1998. MMW/R Morb Mortal W/kly Rep. 1999;48:243-248

5. Ibrahim SA, Whittle J, Bean-Mayberry B, Kelley ME, Good C, Conigliaro J. Racial/ethnic variations in physician recommendations for cardiac revascularization. Am J Public Health. 2003;93:1689-1693.

6. Smedley B, Stith A, Nelson A, eds. Unequal Treatment: Confronting Racial and Ethnic Disparities in Health Care. Washington, DC: National Academy Press; 2002.

7. Office of Budget, US Department of Health and Human Services. FY 2006 Budget in Brief. Available at: http://www.hhs.gov/budget/ 06budget. Accessed 28 March 2006.

8. PhRMA chief medical officer testifies on DTC advertising [press release]. Washington, DC: PhRMA; September 4, 2005. Available at: http://www.phrma.org/news_room/press_releases/phrma_chief_medical_officer_testifies_on_dtc_advertising/. Accessed 8 August 2006 .

9. Oldham J. Sic Evenit Ratio Ut Componitur: The Small Book About Large System Change. Chichester, England: Kingsham Press Ltd; 2005.

10. Blumenthal D, Jennison Goonan K, Causion N. Promoting Quality Improvement at Academic Health Centers: Building on Pursuing Perfection. Boston, Mass: Institute for Health Policy; 2003. 